\title{
REVISED FOOD AND DRUG ADMINISTRATION RISK CATEGORIES OF DRUGS DURING PREGNANCY
}

Sir,

In the changing scenario of today's world, many women are conceiving at a later age, and there is an increase in pregnant women requiring drug treatment for chronic conditions such as diabetes, hypertension, epilepsy, or asthma. It is not possible to withhold drug therapy in such cases as these conditions may endanger the lives of both mother and baby. It thus becomes essential that both health-care provider and the woman, have accessible, cognizable and unambiguous pregnancy and lactation information to assess risk versus benefit while opting for a drug treatment $[1,2]$. However, there is a greater appreciation for risks involved with drug use in pregnancy and physicians mostly adhere to the prescription guidelines [3,4].

The existing letter risk categorization of drugs (A, B, C, D, and X) was often confusing to both physicians and the patients and led to a lot of misinformation. The risk versus benefit assessment was also often difficult. To alleviate these concerns, the U.S. Food and Drug Administration decided to implement the pregnancy and lactation labeling final rule (PLLR) which came into effect on June 30,2015. This rule was designed to improve risk versus benefit assessment of drugs used in pregnant and nursing mothers. It is intended to provide clear and detailed information for both patients and health-care providers in narrative sections under three main categories - pregnancy, lactation, and females and males of reproductive potential $[5,6]$.

The pregnancy category will deal with information pertaining to the use of drugs in pregnant women, like dosing and probable risks to the developing fetus, and also information about whether there is a registry that collects and maintains data on the effects of the drug or biological product on pregnant women. The lactation category will consist of information about using medications during breastfeeding, such as the amount of drug secreted in breast milk and possible effects on the breastfed child. The females and males of the reproductive potential category will provide data about pregnancy testing, contraception, and about infertility as it relates to the drug. Although this information has been included in labeling, there was no particular categorization for it until now [7].

While the implementation of this new rule will provide elaborate and accurate information to health-care providers when making decisions about drug therapy in patients who are pregnant and breastfeeding, it also entrusts larger responsibility on the practitioners to ensure the safety of their patients. The physicians have to make more of an effort to be well-educated and aware about risks and benefits associated with the prescribed drug [5]. The misinterpretation of risk of drugs in the old pregnancy letter category system that has overwhelmed practitioners and patients will definitely be minimized by PLLR; however, over-thecounter medications will still be subject to the old system. A time period of 3-5 years may be necessary for implementation and smooth operation of the rule, but the labeling of drugs is a step in the right direction [8].

\section{AJITHA SHARMA, RATHNAKAR UP}

Department of Pharmacology, Kanachur Institute of Medical Sciences, Deralakatte, Mangalore, Karnataka, India. Email: drajithasharma@gmail.com

Received: 10 December 2016, Revised and Accepted: 14 April 2017

\section{REFERENCES}

1. FDA Pregnancy Categories. FDA Pregnancy Risk Information: An Update. Available from: https://www.drugs.com/pregnancy-categories. html. [Last accessed on 2016 Nov 30].

2. Law R, Bozzo P, Koren G, Einarson A. FDA pregnancy risk categories and the CPS: Do they help or are they a hindrance? Can Fam Physician 2010;56(3):239-41.

3. Priya PP, Rajesh K, Reddy KP, Devi VR. Pattern of drug use in pregnant women and evaluating the effect of supplements on growth of fetus. Int J Pharm Pharm Sci 2013;5(4):651-4.

4. Agarwal M, Nayeem M, Safhi MM, Makeen HA, Sumaily JM, Gupta N. Prescribing pattern of drugs in the department of obstetrics and gynaecology in expecting mothers in Jazan region, KSA. Int J Pharm Pharm Sci 2014;6(1):658-61.

5. Mosley JF $2^{\text {nd }}$, Smith LL, Dezan MD. An overview of upcoming changes in pregnancy and lactation labeling information. Pharm Pract (Granada) 2015;13(2):605.

6. Pregnancy and Lactation Labeling (Drugs) Final Rule. December 3; 2014. Available from: http://www.fda.gov/Drugs/ DevelopmentApprovalProcess/DevelopmentResources/Labeling/ ucm093307.htm. [Last accessed on 2016 Nov 30].

7. FDA News Release. FDA Issues Final Rule on Changes to Pregnancy and Lactation Labeling Information for Prescription Drug and Biological Products. December 3; 2014. Available from: http://www. fda.gov/NewsEvents/Newsroom/PressAnnouncements/ucm425317. htm. [Last accessed on 2016 Nov 30].

8. Lim L, Thompson K. New prescription drug labeling for pregnant or nursing women. Pharm Today 2016;22:40-1. 